\title{
Preimplantation genetic diagnosis of hemophilia A
}

\author{
Ming Chen ${ }^{1,2,3,4,5,6^{*}+}$, Shun-Ping Chang ${ }^{1,2 \dagger}$, Gwo-Chin Ma ${ }^{1,2,7,8+}$, Wen-Hsian Lin ${ }^{1,2}$, Hsin-Fu Chen ${ }^{3}$, Shee-Uan Chen ${ }^{3}$,
} Horng-Der Tsai ${ }^{7}$, Feng-Po Tsai ${ }^{9}$ and Ming-Ching Shen ${ }^{10}$

From The 9th Congress of the Asian-Pacific Society on Thrombosis and Hemostasis

Taipei, Taiwan. 6-9 October 2016

\begin{abstract}
Preimplantation genetic diagnosis (PGD) is a powerful tool to tackle the transmission of monogenic inherited disorders in families carrying the diseases from generation to generation. It currently remains a challenging task, despite PGD having been developed over 25 years ago. The major difficulty is it does not have an easy and general formula for all mutations. Different gene locus needs individualized, customized design to make the diagnosis accurate enough to be applied on PGD, in which the quantity of DNA is scanty, whereas timely laboratory diagnosis is mandatory if fresh embryo transfer is desired occasionally. Indicators for outcome assessment of a successful PGD program include the successful diagnosis rate on blastomeres (Day 3 cleavage-stage embryo biopsy) or trophectoderm cells (Day 5/6 blastocyst biopsy), the implantation rate per embryo transferred, and the livebirth rate per oocyte retrieval cycle. Hemophilia A (HA) is an X-linked recessive bleeding disorder caused by various types of pathological defects in the factor VIII gene (F8). The mutation spectrum of the F8 is complex, according to our previous report, including large segmental intra-gene inversions, large segmental deletions spanning a few exons, point mutations, and total deletion caused by chromosomal structural rearrangements. In this review, the molecular methodologies used to tackle different mutants of the F8 in the PGD of HA are to be explained, and the experiences of successful use of amplification refractory mutation system-quantitative polymerase chain reaction (ARMS-qPCR) and linkage analysis for PGD of HA in our laboratory are also provided.
\end{abstract}

Keywords: PGD, ARMS-qPCR, Linkage analysis, STR marker, Polymorphism

Abbreviations: $A D O$, Allele dropout; ARMS-qPCR, Amplification refractory mutation system-quantitative polymerase chain reaction; FISH, Fluorescence in situ hybridization; HA, Hemophilia A; HGMD, Human gene mutation database; INV1, Intron 1 inversion; INV22, Intron 22 inversion; I-PCR, Inverse polymerase chain reaction; long-distance PCR, Long-distance polymerase chain reaction; MLPA, Multiplex ligation-dependent probe amplification; NGS, Next generation sequencing; PGD, Preimplantation genetic diagnosis; PGS, Preimplantation genetic screening; STR, Short tandem repeat; WGA, Whole genome amplification

\footnotetext{
* Correspondence: mingchenmd@gmail.com; mchen_cch@yahoo.com

${ }^{\dagger}$ Equal contributors

'Department of Genomic Medicine and Center for Medical Genetics,

Changhua Christian Hospital, Changhua, Taiwan

${ }^{2}$ Department of Genomic Science and Technology, Changhua Christian

Hospital Healthcare System, Changhua, Taiwan

Full list of author information is available at the end of the article
} 


\section{Background}

Preimplantation genetic diagnosis (PGD) had become a standard of care when dealing with stopping the transmission of the heritable disease from generation to generation since it was firstly introduced in 1990 [1, 2]. The gold standard of molecular technology used for PGD nowadays is the coamplification of the polymorphic microsatellite linkage markers [3, 4]. However, such techniques cannot avoid the possibility of recombination occurred within the segment which separated the linked polymorphic markers and the disease loci, and it is advised to combine more informative linkage markers to reduce the chance of misdiagnosis. On the other hand, direct mutation detection assay, either rapid PCR-based or the more time-consuming sequencing-based genotyping platforms, is prone to allele dropout (ADO), which may ensue a catastrophic false-negative misdiagnosis in PGD of autosomal dominant monogenic disorder $[4,5]$.

Hemophilia A (HA) (OMIM 306700), a bleeding disorder which causes long-term disability, is a X-linked recessive disorder and its causative gene is situated at $\mathrm{Xq} 28$, the factor VIII (F8) gene, is a serious threat for public health in Taiwan, and we had first published its mutation spectrum in the Taiwanese population in 2008 [6]. The mutation spectrum included rearrangements such as intron 1 inversions (INV1) and intron 22 inversions (INV22), large deletions spanning for consecutive exons, small deletions involving only a few base pairs, and point mutations [6]. The broad spectra of F8 mutations have also been reported in several other studies [7-9]. The genotyping itself for the $F 8$ is already a daunting task given its complicated existing mutations patterns, let alone the PGD. In spite of the challenges, we managed to tackle these difficulties in a few families who came to our hospital seeking for PGD. Meanwhile, a few similar efforts had been reported from other laboratories $[10,11]$, which indicates PGD for HA is feasible, at least in those families the mutation has been confirmed. Here we will give a concise review of PGD for $\mathrm{HA}$, including the different molecular technologies used to tackle different mutation patterns, and also to cite a few of our experience with successful outcome, that is, to give birth to normal unaffected babies in families suffered from HA.

\section{Review}

Mutation spectrum of the F8 gene, genotyping strategies, and possible PGD approaches

Since the publication of the sequence of the F8 in 1984, more than 2000 gene mutations causing HA have been described and these are catalogued in the Human Gene Mutation Database (HGMD; http://www.hgmd.cf.ac.uk/ ac/index.php) and Factor VIII Variant Database (http:// www.factorviii-db.org/). In 2008, we had first published the mutation spectrum in the Taiwanese population [6]. Of 31 unrelated HA patients (19 severe and 10 moderate/mild males, and 2 severe females), 12 (38.7 \%) and 1 $(3.2 \%)$ severe males were genotyped with INV22 and INV1 respectively. The F8 defects in the remaining 18 inversion-negative patients cover a wide spectrum, in which 17 different mutations were identified $(10 \mathrm{mis}-$ sense and 3 nonsense mutations, and 2 small and 2 large deletions). Eleven of these mutations are novel and unique, confirming a high diversity of molecular defects in HA [6]. A systematic review for data from 30 studies on 5383 patients had been reported and showed $45 \%$ of HA had INV22, $2 \%$ INV1, 3 \% large deletions, $16 \%$ small deletions or insertions, and $28 \%$ point mutations (15\% missense mutations, $10 \%$ nonsense mutations, and $3 \%$ splicing site mutations). In $4.6 \%$ of patients, the mutation was unknown [12]. Overall, with the exceptions of recurrent INV22 and INV1, no mutation hot spots have been identified.

There are a number of different approaches for the genotyping of HA (Table 1). For reasons of rapid and smart screening, however, targeted mutation analysis for the recurrent INV22 and INV1 has become the first test assessed in patients (particularly in severely affected hemophiliacs). INV22 can be detected by Southern blotting or, more time- and labor-saving choice, by long-distance polymerase chain reaction (long-distance PCR) or inverse PCR (I-PCR) [13, 14]. INV1 is typically detected by multiplex PCR [15]. Other mutations responsible for HA are mostly point mutation and small deletion/insertion in the $F 8$ gene and their spectrum is quite complex. In these cases, mutation can be detected by PCR with a number of screening methods (e.g., single strand conformational polymorphism, conformation sensitive gel electrophoresis, amplification and mismatch detection, denaturing gradient gel electrophoresis) followed by direct DNA sequencing [16-21]. For female patients with only one mutation detected and also in those females suspected to be carriers but no mutation could be found, gene dosage assays such as multiplex ligation-dependent probe amplification (MLPA) should be applied to screen for the underlying exon deletions since deletions in single allele usually escape detection by the PCR-based analysis, due to the masking of the non-deleted allele. In Fig. 1, we exemplified the MLPA finding of a female HA patient who was karyotyped as 45,X [22]/46,X,idic(X)(q21) [8] mosaicism. Her aberrant X-chromosome (idic(X)(q21)) do not contain the $\mathrm{Xq} 22 \mathrm{q} 28$ (and thus F8 gene) and familiar follow-up studies demonstrate this anomaly is of de novo. PCR amplification for exon1-22 of the $F 8$ is failure in patient but is successful in her parents. Through the MLPA analyses, it is evidenced that the patient carries an exon 1-22 deletion in the allele on her "morphologically-normal" $\mathrm{X}$ chromosome, which is inherited from her mother (Fig. 1). 
Table 1 Genotype-phenotype relationship, genetic testing and preimplantation genetic diagnosis (PGD) in hemophilia A

\begin{tabular}{|c|c|c|c|c|}
\hline Mutation type & Frequency of occurrance ${ }^{a}$ & Clinical severity $^{\mathrm{b}}$ & Test method & PGD method \\
\hline $\begin{array}{l}\text { Inversion } \\
\text { - INV22 } \\
\text { - INV1 }\end{array}$ & $\begin{array}{l}47 \% \\
\cdot 45 \% \\
\cdot 2 \%\end{array}$ & Severe & $\begin{array}{l}\text { - I-PCR (for INV22) } \\
\text { - Long-distance PCR (for INV22) } \\
\text { - Southern blotting (for INV22) } \\
\text { - Multiplex PCR (for INV1) }\end{array}$ & - Linkage analysis \\
\hline $\begin{array}{l}\text { Point mutation } \\
\text { - Missense } \\
\text { - Nonsense } \\
\text { - Splicing site }\end{array}$ & $\begin{array}{l}28 \% \\
\cdot 15 \% \\
\cdot 10 \% \\
\cdot 3 \%\end{array}$ & $\begin{array}{l}\text { Mild, Moderate, Severe } \\
\text { - Mild, Moderate (majority) } \\
\text { - Severe (majority) } \\
\text { - Severe (majority) }\end{array}$ & Direct DNA sequencing & $\begin{array}{l}\text { - ARMS-qPCR } \\
\text { - Linkage analysis }\end{array}$ \\
\hline Small deletion/insertion ( $<1$ exon) & $16 \%$ & Severe (majority) & Direct DNA sequencing & $\begin{array}{l}\text { - ARMS-qPCR } \\
\text { - Linkage analysis }\end{array}$ \\
\hline Large deletion ( $\geq 1$ exon) & $3 \%$ & Severe (majority) & MLPA & - Linkage analysis \\
\hline Others (e.g., Complex rearrangement) & NA & Severe (majority) & Depending on mutation entities & - Linkage analysis \\
\hline
\end{tabular}

MLPA multiplex ligation-dependent probe amplification, I-PCR inverse polymerase chain reaction, ARMS amplification refractory mutation system, NA not available ${ }^{\text {a }}$ See the review in Gouw et al., [12]

${ }^{\mathrm{b}} \mathrm{HA}$ patients are clinically divided into three different severities based on the residual FVIII coagulant activity (FVIII:C): severe (FVIII:C $<1 \%$ of normal level), moderate (FVIII:C is $1-5 \%$ of normal level) and mild (FVIII:C is $5-30 \%$ of normal level)

a

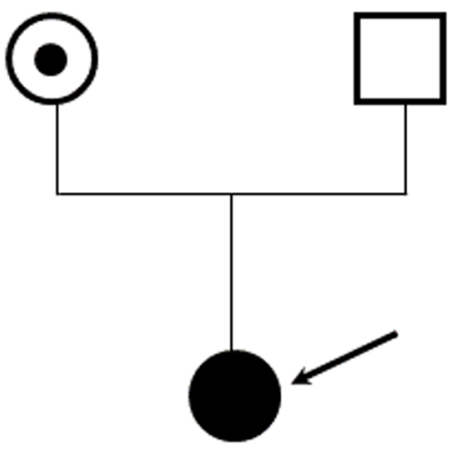

$45, \mathrm{X}[22] / 46, \mathrm{X}, \mathrm{idic}(\mathrm{X})(\mathrm{q} 21)[8]$

b
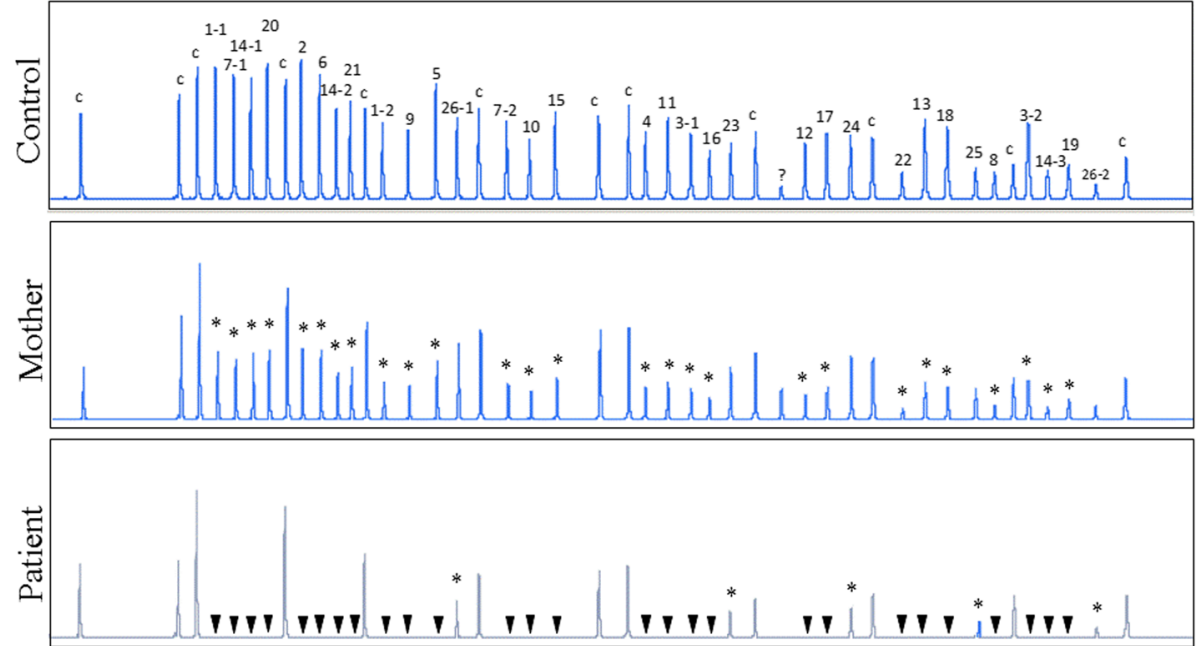

Fig. 1 Genetic testing for a female patient (indicated by an arrow) with severe hemophilia A. a Cytogenetic analysis identifies a 45,X [22]/46,X,idic(X)(q21) [8] mosaicism, indicating at least one F8 allele loss. b MLPA analysis for the F8 gene of the patient detects only copy of exon 23-26 peaks indicating an exon 1-22 deletion in the allele on her "morphologically-normal" X-chromosome. MLPA for the patient's mother detects about 1/2 DNA dosage of exon1-22 indicating a carrier of exon 1-22 deletion. Arabic numbers, the exon numbers of the F8 gene. " $\mathrm{C}$ ", the internal controls used in MLPA. "?", an unexpectedly amplified peck which is not illustrated in the instruction of the MLPA FVIII kit, SALSA P178. "**", loss of one copy in exons. " $\boldsymbol{\nabla}^{\prime \prime}$, loss of two copies in exons 
Given the marked morbidity associated with severe HA, PGD has become a feasible option for couples at risk of having a child with HA since it reduces the risk of termination of affected pregnancies. Gender selection by fluorescence in situ hybridization (FISH) and transfer of only female embryos is a simple strategy for X-linked recessive disorders, such as $\mathrm{HA}$, and has been adopted in many clinics [11]. However, in practice, gender selection is illegal in some countries (e.g., Taiwan) and methods allowing the correct and more definitive diagnosis of the HA status of every embryo are more desirable because the number of embryos available for transfer is increased. PGD involving whole genome amplification (WGA) step was broadly applied to mutation detection strategies, but the high rate of amplification bias renders WGA an imperfect option [22]. Recently, co-amplification of polymorphic microsatellite markers, linked with the targeted mutation, had been the goldstandard genotyping strategy for PGD $[4,23-26]$ (Table 1). A linkage approach using polymorphic markers located near the mutation allows monitoring the occurrence of allele dropout, a known problem associated with PCR amplification bias in PGD. Below, we describe our experience with two HA families seeking for PGD.

\section{Experience of PGD of hemophilia $A$ in our laboratory}

Two Taiwanese couples were referred to our center for PGD of HA. Preliminary genetic testing of $F 8$ for two couples showed the two wives are both HA carriers: one has a splicing site mutation, c.1538-1G > A, and the other has a common INV22. For the family with c.1538$1 G>A$ mutation, an in-house developed duplex-nested ARMS-qPCR was customized designed for PGD [4, 5]. The optimized PGD protocol was then performed to detect the disease-causing mutation in embryos acquired after ovarian stimulation. Seven single blastomeres biopsied from corresponding day-3 (8-cell cleavage-stage) embryos were collected and examined independently in a sterile PCR tube. Each blastomere cell was lysed with $125 \mu \mathrm{g} / \mathrm{mL}$ proteinase $\mathrm{K}$ at $50{ }^{\circ} \mathrm{C}$ for $60 \mathrm{~min}$ and inactivated at $99{ }^{\circ} \mathrm{C}$ for $4 \mathrm{~min}$. Duplex-nested PCR was then used to amplify the intron 10-11 region of $F 8$ gene, which includes the targeted mutation. The two primer sets, designed based on the reverse strand's $F 8$ gene sequence, were OF: CTGAGGACCCATTACCCTGA and OR: CCTGCAACAGTGCTACATGC for the first PCR (amplicon size: 937 bp), and IF: CTTGCTCC CTTTCCTCACAG and IR: TGGGGAGGATCAGCTAGAGA for the secondary PCR (amplicon size: $757 \mathrm{bp}$ ) (Fig. 2a). The first PCR was carried out in a $40 \mu \mathrm{L}$ reaction, consisting of $1 \mathrm{X}$ PCR buffer, $1.25 \mathrm{mmol} / \mathrm{L} \mathrm{MgCl}_{2}$, $0.35 \mathrm{mmol} / \mathrm{L} \mathrm{dNTP}$, each $0.5 \mu \mathrm{mol} / \mathrm{L}$ of $\mathrm{OF}$ and OR primer, 1X GC-RICH solution, and 1U Faststart Taq
DNA polymerase (Roche Diagnostics $\mathrm{GmbH}$, Mannheim, Germany). The cycling conditions were $95{ }^{\circ} \mathrm{C}, 5 \mathrm{~min}$, followed by 25 cycles of $95{ }^{\circ} \mathrm{C}, 30 \mathrm{~s}, 55^{\circ} \mathrm{C}, 30 \mathrm{~s}$ and $71{ }^{\circ} \mathrm{C}, 1 \mathrm{~min}$, and a final extension at $71{ }^{\circ} \mathrm{C}, 2 \mathrm{~min}$. The PCR products were directly subjected to the second round of PCR by adding $10 \mu \mathrm{L}$ PCR supplement with a similar PCR mixture to that used in the first PCR, except for the primer set (IF and IR). Cycling conditions were similar to the first PCR, but the number of cycles in the second step was increased from 25 to 40 . To ensure an accuracy of the PCR, amplified fragments were confirmed by direct sequencing. For ARMS-qPCR, two sequence-specific forward primers, modified with a mismatch at the penultimate nucleotide position of the mutation site to increase the specificity of the reaction, were designed: (MUF: TATGGTTTTGCTTGTGGGT GA for the mutant allele and WTF: TATGGTTTT GCTTGTGGGTGG for the wild-type allele). The two forward primers were respectively paired with the same reverse primer 3rdR: TGAGGAGAGGGCCAATGAGT (amplicon size:198 bp) (Fig. 2b). The ARMS-qPCR performed on the LightCycler 480 Real-Time PCR System (Roche, Mannheim, Germany) in a $20 \mu \mathrm{L}$ reaction, consisted of $0.5 \mathrm{ng}$ of the duplex-nested PCR product, $0.5 \mu \mathrm{mol} / \mathrm{L}$ of each primer, $1 \mathrm{X}$ SYBR Green PCR Master Mix (Finnzymes, Espoo, Finland). Cycling conditions were: $95{ }^{\circ} \mathrm{C}, 10 \mathrm{~min}$, followed by 45 cycles at $95{ }^{\circ} \mathrm{C}, 10 \mathrm{~s}, 60^{\circ} \mathrm{C}$ and $60 \mathrm{~s}$. The exemplified results of ARMS-qPCR were shown in Fig. 2c. Of the seven blastomeres examined, two were reported as affected embryos with the homo- or hemizygous c.1538-1G > A mutation, one was known as a heterozygous carrier, and the remaining four were presented as same as wildtype pattern without the mutation. However, only one unaffected embryo kept good morphology and was transferred on day 5. After 39 weeks of uneventful gestation, one healthy baby girl was born successfully with a birth weight of 3040 g. Postnatal genotyping confirmed the girl to be an unaffected carrier and, interestingly, she was HLA-compatible with her older brother affected by HA (see family 1 in Fig. 3).

The INV22 of $F 8$ is one of the most frequent cause of severe $\mathrm{HA}$, known as a result of homologous recombination between the int $22 \mathrm{~h}-1$ region within the $F 8$ locus and either int22h-2 (Inv22 type II) or int22h-3 (Inv22 type I), which lie nearly $400 \mathrm{~kb}$ distal to $F 8$ [27]. The gene rearrangements tend to increase the difficulty of PGD experimental design performed in the affected families. In the second PGD family with F8 INV22 mutation, the couple (2-1 and 2-2) has had a healthy boy and they would like to get more babies without HA. We performed 3 PGD cycles of HA during the period of Sep. 2014 to Dec. 2015 using short tandem repeat (STR) markers and capillary electrophoresis for direct linkage 


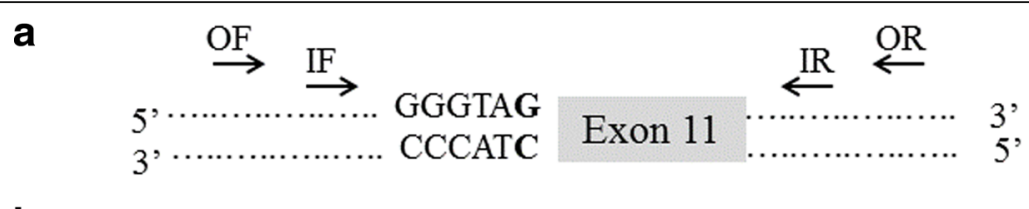

b
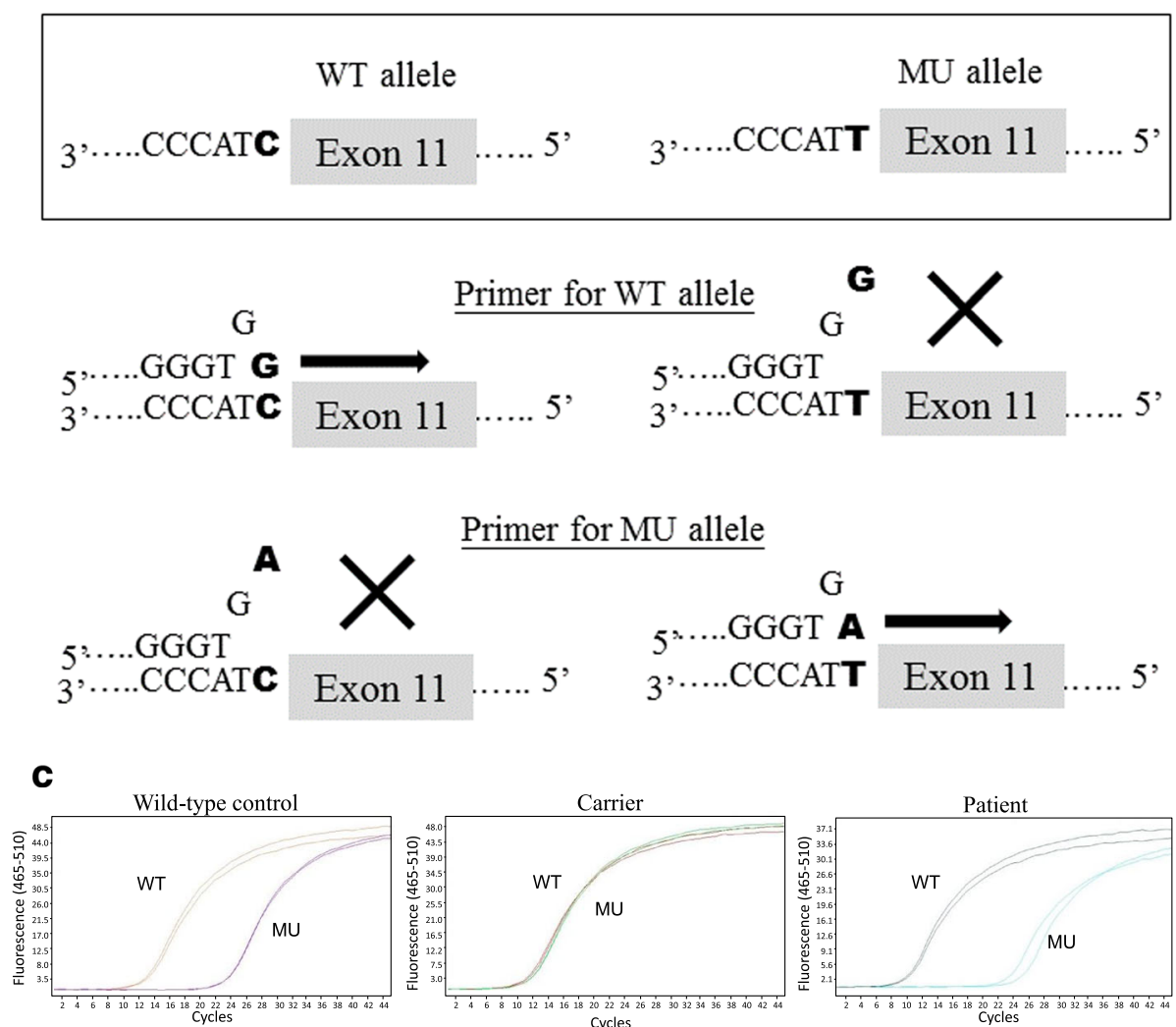

Fig. 2 Schematic diagram of a duplex-nested ARMS-qPCR for PGD of a splicing-site point mutation, located at the junction of intron 10 and exon 11 of F8, C.1538-1G > A (bold letter). a Primers for duplex-nested PCR were first designed to amplify the region covering the position of the mutation. OF and OR indicate the outer primer set, and IF and IR indicate inner primer set. $\mathbf{b}$ Primers specific for the amplification of the wild-type (WT) and mutant (MU) alleles, respectively, were subsequently used for ARMS-qPCR where the duplex-nested PCR amplicon was used as DNA template. c Representative ARMS-qPCR results for wild-type control (homozygous WTMT or hemizygous WT), female carrier (heterozygous WT/MU), and affected male individual (hemizygous MU)

analysis. Five informative STR markers distributed within or near the flanking region of the $F 8$ were selected for PGD performing (see family 2 in Fig. 3). Among a total of 19 examined embryos, 5 wild types and 4 INV22 carriers were selected and transferred during the period. Unfortunately, pregnancy outcome did not occur as expected, possibly due to ad maternal age, embryo morphology, development and other abnormalities. Despite the fact that no pregnancy was achieved in the PGD experience so far, they are still willing to keep trying.

\section{Discussion}

The outcome indicators of PGD can be classified as successful diagnosis rate (the number of embryos which diagnosis was made/the total number of embryos being biopsied), implantation rate (the number of embryos implanted/the total number of embryos being transferred), and the live-birth rate (the rate of liveborn pregnancy per transferred cycle or the rate of liveborn pregnancy per oocyte-retrieval). It is now still under debate whether frozen or fresh embryo transfer can achieve a better outcome against the other. However, it is vitally important that PGD laboratories developed a timely genotyping platform to cope with the need of fresh embryo transfer, especially when Day $5 / 6$ blastocyst biopsy is undertaken. For rapid PGD of HA, the direct mutation detection, e.g., ARMS-qPCR, can greatly increase the reliability of mutation detection in embryos with small insertions/ deletion and point mutations (see the exemplified 


\begin{tabular}{|c|c|c|c|c|c|c|c|c|}
\hline \multicolumn{4}{|c|}{ Family 1} & \multicolumn{5}{|c|}{ Family 2} \\
\hline \multirow{2}{*}{ STR marker } & \multicolumn{4}{|l|}{ Family 1} & \multicolumn{3}{|c|}{ Family 2} & \\
\hline & $1-1$ & $1-2$ & $1-3$ & $1-4$ & $2-1$ & $2-2$ & $2-3$ & $2-4$ \\
\hline \multicolumn{9}{|l|}{ F8-linked } \\
\hline DXS9901 & 205 & 203,205 & 203 & 203,205 & 205 & 193,205 & 193 & 193 \\
\hline F8 int 9.2 & 134 & 134,136 & 134 & 134 & 133 & 133,135 & 133 & 133 \\
\hline F8 CIVS13 & 151 & 151,153 & 151 & 151 & 150 & 153 & 153 & 153 \\
\hline FS int 21 & 211 & 207,211 & 211 & 211 & 210 & 206,210 & 210 & 210 \\
\hline F8 CIVS 22 & 211 & 209,211 & 211 & 211 & 210 & 208 & 208 & 208 \\
\hline & 205 & 203,205 & 203 & 203,205 & & & & \\
\hline \multicolumn{9}{|l|}{ HLA-typing } \\
\hline D6S510 & 141,153 & 154,158 & 141,154 & 141,154 & TNP & TNP & TNP & TNP \\
\hline D6S273 & 145 & 153 & 145,153 & 145,153 & $\mathrm{TNP}$ & TNP & TNP & TNP \\
\hline DRA-CA & 125,136 & 124,136 & 124,136 & 124,136 & TNP & TNP & TNP & TNP \\
\hline HLABC & 127,143 & 135,145 & 135,143 & 135,143 & TNP & TNP & TNP & TNP \\
\hline DQCAR & 157,171 & 167,169 & 167,171 & 167,171 & TNP & TNP & TNP & TNP \\
\hline MIB & 160,166 & 160,185 & 160,185 & 160,185 & TNP & TNP & TNP & TNP \\
\hline D6S2447 & 185,199 & 195,197 & 195,199 & 195,199 & TNP & TNP & TNP & TNP \\
\hline D6S51624 & 202,204 & 202,204 & 202,203 & 201,203 & TNP & TNP & TNP & TNP \\
\hline TAPICA & 201,218 & 201,203 & 201 & 201 & TNP & TNP & TNP & TNP \\
\hline $\mathrm{D} 3 \mathrm{~A}$ & 203,205 & 203,207 & 203,205 & 203,205 & TNP & TNP & TNP & TNP \\
\hline D6S291 & 164,174 & 164,168 & 164,168 & 164,168 & TNP & TNP & TNP & TNP \\
\hline D6S265 & 125,139 & 129 & 125,129 & 125,129 & TNP & TNP & TNP & TNP \\
\hline \multicolumn{9}{|c|}{$\begin{array}{l}\text { TNP, test not performed. } \\
\text { Fig. } 3 \text { Exemplified PGD of F8 defects for two hemophilia A families: family } 1 \text { (c.1538-1G > A mutation) and family } 2 \text { (INV22). PGD was performed } \\
\text { using ARMS-qPCR, together with linkage analysis for five informative short tandem repeat (STR) markers ordered from centromere (top) to telomere } \\
\text { (bottom). The numbers in STR markers represent the sizes of PCR amplicons in base pair (bp). In family 1, human leukocyte antigen (HLA) typing with } \\
\text { 12 STR markers was also performed. PGD for hemophilia A resulted in a birth of healthy girl (1-4), who was HLA matched to the affected sibling (1-3). } \\
\text { In family 2, PGD for INV22 was directly performed by linkage analysis. The maternal allele linked to INV22 was evidenced by comparing the STR profile } \\
\text { with that of case 2-3 and 2-4. In the pedigree, squares represent males, and circles represent females. Line through, filled, dotted and open the } \\
\text { symbols represent deceased, affected, carrier and unaffected individuals respectively }\end{array}$} \\
\hline
\end{tabular}

couple 1). However, for large and complex F8 defects, e.g., INV1 and INV22, PGD by direct genotyping is not easily feasible and indirect linkage analysis with informative markers may be considered (see the exemplified couple 2). Of noted, the chance of recombination between the markers and mutation can lead to small diagnostic error 
and some families may not be informative for any of the available markers.

Recently, it is noteworthy that because of the popularity of preimplantation genetic screening (PGS), there is a growing need of concurrent PGD/PGS. At the moment the strategies used in PGS, if we exclude the outdated FISH-based diagnostics [28], include array-based (either array comparative genomic hybridization or single nucleotide polymorphism chromosomal microarray) techniques [29-31], q-PCR based techniques [32, 33], and next generation sequencing (NGS)-based techniques $[34,35]$. Some of the techniques had been reported to successfully being applied in PGD combined with PGS [36-39]. It is inevitable that in the near future, women will opt for select the unaffected embryos with certain heritable monogenic disorders, such as HA, as well as the euploid embryos which will reduce the chance of abortion due to aneuploidy in the later gestational period or improved the implantation rate as many researchers advocated [40]. However, it will be undisputable only after more convincing randomized trials to prove the efficacy of PGS, the combination of PGD and PGS should be offered to all women underwent PGD [41]. Those couple who opted for PGD combined with PGS should be counseled that double selection will inevitable reduce the number of embryos which are classified as "suitable" for transfer, thereby reducing all the outcome indicators of PGD, the most important live-birth rate is certainly included.

\section{Conclusions}

PGD of HA by direct mutation analysis or indirect linkage analysis has become a feasible option for couples at risk of having an affected child. However, given the broad spectra of the F8 mutations, genetic counseling along with the technical aspects of the accuracy and limitations of tests should be provided for couples who request PGD.

\section{Acknowledgements \\ This study was partially supported by grants from Changhua Christian Hospital to $M$. Chen and to M-C. Shen. \\ Declaration \\ Publication fees for this article have been funded by APSTH 2016. This article has been published as part of Thrombosis Journal Volume 14 Supplement 1, 2016. The full contents of the supplement are available at https://thrombosisjournal.biomedcentral.com/articles/supplements/ volume-14-supplement-1.}

\section{Availability of data and material}

The unidentified dataset and material information of this article are available upon request by contacting the corresponding author.

\section{Authors' contributions}

MC, SPC, GCM designed the study. MCS recruited the patients. MCS, HFC, SUC, HDT, FPT collected the clinical data. MC, SPC, GCM, WHL did the experiments and performed the analyses. MC, SPC, GCM wrote the paper. All authors read and approved the final manuscript.

\section{Competing interests}

The authors declare that they have no competing interests.
Consent for publication

Not applicable.

Ethics approval and consent to participate

Not applicable.

\section{Author details}

${ }^{1}$ Department of Genomic Medicine and Center for Medical Genetics, Changhua Christian Hospital, Changhua, Taiwan. 'Department of Genomic Science and Technology, Changhua Christian Hospital Healthcare System, Changhua, Taiwan. ${ }^{3}$ Department of Obstetrics and Gynecology, College of Medicine and Hospital, National Taiwan University, Taipei, Taiwan.

${ }^{4}$ Department of Medical Genetics, National Taiwan University Hospital, Taipei, Taiwan. ${ }^{5}$ Department of Life Science, Tunghai University, Taichung, Taiwan. ${ }^{6}$ Department of Obstetrics and Gynecology, Changhua Christian Hospital, Changhua, Taiwan. ${ }^{7}$ Institute of Biochemistry, Microbiology and Immunology, Chung Shan Medical University, Taichung, Taiwan. ${ }^{8}$ Department of Medical Laboratory Science and Biotechnology, Central Taiwan University of Science and Technology, Taichung, Taiwan. ${ }^{9}$ Po-Yuan Women's Clinic and IVF Center, Changhua, Taiwan. ${ }^{10}$ Department of Internal Medicine, and Thrombosis and Hemostasis Center, Changhua Christian Hospital, Changhua, Taiwan.

Published: 4 October 2016

\section{References}

1. Handyside A, Kontogianni EH, Hardy K, Winston RM. Pregnancies from biopsied human preimplantation embryos sexed by $Y$-specific DNA amplification. Nature. 1990;344:768-70.

2. Brezina PR, Brezina DS, Kearns WG. Preimplantation genetic testing. BMJ. 2012;345:e5908.

3. Harton GL, De Rycke M, Fiorentino F, Moutou C, SenGupta S, TraegerSynodinos J, et al. European Society for Human Reproduction and Embryology (ESHRE) PGD Consortium: ESHRE PGD consortium best practice guidelines for amplification-based PGD. Human Reprod. 2011;26:33-40.

4. Chen HF, Chang SP, Wu SH, Lin WH, Lee YC, Ni YH, et al. Validating a rapid, real-time, PCR-based direct mutation detection assay for preimplantation genetic diagnosis. Gene. 2014;548:299-305.

5. Kuo SJ, Ma GC, Chang SP, Wu HH, Chen CP, Chang TM, et al. Preimplantation and prenatal genetic diagnosis of aromatic L-amino acid decarboxylase deficiency with an amplification-refractory mutation system-quantitative polymerase chain reaction. Taiwan J Obstet Gynecol. 2011;50:468-73.

6. Ma GC, Chang SP, Chen M, Kuo SJ, Chang CS, Shen MC. The mutation spectrum of the factor 8 (F8) defects in Taiwanese patients with severe hemophilia A. Haemophilia. 2008;14:787-95.

7. Bogdanova N, Markoff A, Pollmann H, Nowak-Göttl U, Eisert R, Wermes C, et al. Spectrum of molecular defects and mutation detection rate in patients with severe hemophilia A. Hum Mutat. 2005:26:249-54

8. Guillet B, Lambert T, d'Oiron R, Proulle V, Plantier JL, Rafowicz A, Peynet J, et al. Detection of 95 novel mutations in coagulation factor VIII gene F8 responsible for hemophilia A: results from a single institution. Hum Mutat. 2006;27:676-85.

9. Bogdanova N, Markoff A, Eisert R, Wermes C, Pollmann H, Todorova A, et al. Spectrum of molecular defects and mutation detection rate in patients with mild and moderate hemophilia A. Hum Mutat. 2007;28:54-60.

10. Laurie AD, Hill AM, Harraway JR, Phillipson GT, Benny PS, Smith MP, et al. Preimplantation genetic diagnosis of hemophilia A using indirect linkage analysis and direct genotyping approaches. J Thrombo Haemost. 2010;8:783-9.

11. Fernández RM, Peciña A, Sánchez B, Lozano-Arana MD, García-Lozano JC, Pérez-Garrido R, et al. Experience of preimplantation genetic diagnosis for hemophilia at the University Hospital Virgen Del Rocio in Spain: Technical and clinical overview. Biomed Res Int. 2015;2015:406096.

12. Gouw SC, van den Berg HM, Oldenburg J, Astermark J, de Groot PG, Margaglione $M$, et al. F8 gene mutation type and inhibitor development in patients with severe hemophilia A: systematic review and meta-analysis. Blood. 2012:119:2922-34.

13. Liu Q, Nozari G, Sommer SS. Single-tube polymerase chain reaction for rapid diagnosis of the inversion hotspot of mutation in haemophilia A. Blood. 1998:92:1458-9.

14. Rossetti LC, Radic CP, Larripa IB, De Brasi CD. Genotyping the hemophilia inversion hotspot by use of inverse PCR. Clin Chem. 2005;51:1154-8.

15. Bagnall RD, Waseem N, Green PM, Giannelli F. Recurrent inversion breaking intron 1 of the factor VIII gene is a frequent cause of severe hemophilia A. Blood. 2002;99:168-74 
16. Tantawy AAG. Molecular genetics of hemophilia A: clinical perspectives. Egypt J Med Hum Genet. 2010;11:105-14.

17. Shetty S, Ghosh K, Mohanty D. Alternate strategies for carrier detection and antenatal diagnosis in haemophilias in developing countries. Indian J Hum Genet. 2003;9:5-9.

18. Mitchell M, Keeney S, Goodeve A. UK Haemophilia Centre Doctors' Organization Haemophilia Genetics Laboratory Network. The molecular analysis of haemophilia A: a guideline from the UK haemophilia centre doctors' organization haemophilia genetics laboratory network. Haemophilia. 2005;11:387-97.

19. Peyvandi F, Jayandharan G, Chandy M, Srivastava A, Nakaya SM, Johnson MJ, et al. Genetic diagnosis of haemophilia and other inherited bleeding disorders. Haemophilia. 2006;12 Suppl 3:82-9.

20. Castaldo G, D'Argenio V, Nardiello P, Zarrilli F, Sanna V, Rocino A, et al. Haemophilia A: molecular insights. Clin Chem Lab Med. 2007;45:450-61.

21. Goodeve A. Molecular genetic testing of hemophilia A. Semin Thromb Hemost. 2008;34:491-501.

22. Renwick PJ, Lewis CM, Abbs S, Ogilvie CM. Determination of the genetic status of cleavage-stage human embryos by microsatellite marker analysis following multiple displacement amplification. Prenat Diagn. 2007;27:206-15.

23. Laurie AD, Hill AM, Harraway JR, Fellowes AP, Phillipson GT, Benny PS, et al. Preimplantation genetic diagnosis for hemophilia A using indirect linkage analysis and direct genotyping approaches. J Thromb Haemost. 2010;8:783-9.

24. Chang $\sqcup$, Huang CC, Tsai YY, Hung CC, Fang MY, Lin YC, et al. Blastocyst biopsy and vitrification are effective for preimplantation genetic diagnosis of monogenic diseases. Hum Reprod. 2013;28:1435-44.

25. De Rycke M, Georgiou I, Sermon K, Lissens W, Henderix P, Joris H, et al. PGD for autosomal dominant polycystic kidney disease type 1. Mol Hum Reprod. 2005;11:65-71.

26. Korzebor A, Derakhshandeh-Peykar P, Meshkani M, Hoseini A, Rafati M, Purhoseini $M$, et al. Heterozygosity assessment of five STR loci located at $5 q 13$ region for preimplantation genetic diagnosis ofspinal muscular atrophy. Mol Biol Rep. 2013;40:67-72.

27. Naylor JA, Buck D, Green P, Williamson H, Bentley D, Gianneill F. Investigation of the factor VIII intron 22 repeated region (int22h) and the associated inversion junctions. Hum Mol Genet. 1995:4:1217-24.

28. Mastenbroek S, Twisk M, van der Veen F, Repping S. Preimplantation genetic screening: a systematic review and meta-analysis of RCTs. Hum Reprod Update. 2011;17:454-66.

29. Schoolcraft WB, Treff NR, Stevens JM, Ferry K, Katz-Jaffe M, Scott Jr RT. Live birth outcome with trophectoderm biopsy, blastocyst vitrification, and single-nucleotide polymorphism microarray-based comprehensive chromosome screening in infertile patients. Fertil Steril. 2011;96:638-40.

30. Treff NR, Levy B, Su J, Taylor D, Scott Jr RT. Development and validation of an accurate quantitative real-time polymerase chain reaction- based assay for human blastocyst comprehensive chromosomal aneuploidy screening. Fertil Steril. 2012;97:819-24.

31. Rubio C, Rodrigo L, Mir P, Mateu E, Peinado V, Milán M, et al. Use of array comparative genomic hybridization (array-CGH) for embryo assessment: clinical results. Fertil Steril. 2013;99:1044-8.

32. Treff NR, Tao X, Ferry KM, Su J, Taylor D, Scott Jr RT. Development and validation of an accurate quantitative real-time polymerase chain reactionbased assay for human blastocyst comprehensive chromosomal aneuploidy screening. Fertil Steril. 2012;97:819-24.

33. Yang YS, Chang SP, Chen HF, Ma GC, Lin WH, Lin CF, et al. Preimplantation genetic screening of blastocysts by multiplex qPCR followed by fresh embryo transfer: validation and verification. Mol Cytogenet. 2015;8:49.

34. Wells D, Kaur K, Grifo J, Glassner M, Taylor JC, Fragouli E, et al. Clinical utilisation of a rapid low-pass whole genome sequencing technique for the diagnosis of aneuploidy in human embryos prior to implantation. J Med Genet. 2014:51:553-62.

35. Ma GC, Chen HF, Yang YS, Lin WH, Tsai FP, Lin CF, et al. A pilot proof-ofprinciple study to compare fresh and vitrified cycle preimplantation genetic screening by chromosome microarray and next generation sequencing. Mol Cytogenet. 2016;9:25.

36. Giménez C, Sarasa J, Arjona C, Vilamajó E, Martínez-Pasarell O, Wheeler K, et al. Karyomapping allows preimplantation genetic diagnosis of a de-novo deletion undetectable using conventional PGD technology. Reprod Biomed Online. 2015;31:770-5.

37. Zimmerman RS, Jalas C, Tao X, Fedick AM, Kim JG, Northrop LE, et al. Development and validation of concurrent preimplantation genetic diagnosis for single gene disorders and comprehensive chromosomal aneuploidy screening without whole genome amplification. Fertil Steril. 2016;105:286-94.

38. Gui B, Yang P, Yao Z, Li Y, Liu D, Liu N, et al. A new next-generation sequencing-based assay for concurrent preimplantation genetic diagnosis of Charcot-Marie-Tooth disease yype 1A and aneuploidy screening. J Genet Genomics. 2016;43:155-9.

39. Goldman KN, Nazem T, Berkeley A, Palter S, Grifo JA. Preimplantation genetic diagnosis (PGD) for monogenic disorders: the value of concurrent aneuploidy screening. J Genet Couns. 2016. [Epub ahead of print]

40. Forman EJ, Hong KH, Franasiak JM, Scott Jr RT. Obstetrical and neonatal outcomes from the BEST Trial: single embryo transfer with aneuploidy screening improves outcomes after in vitro fertilization without compromising delivery rates. Am J Obstet Gynecol. 2014;210:157.e1-6.

41. Yang Z, Lin J, Zhang J, Fong WI, Li P, Zhao R, et al. Randomized comparison of next-generation sequencing and array comparative genomic hybridization forpreimplantation genetic screening: a pilot study. BMC Med Genomics. 2015;8:30.

\section{Submit your next manuscript to BioMed Central and we will help you at every step:}

- We accept pre-submission inquiries

- Our selector tool helps you to find the most relevant journal

- We provide round the clock customer support

- Convenient online submission

- Thorough peer review

- Inclusion in PubMed and all major indexing services

- Maximum visibility for your research

Submit your manuscript at www.biomedcentral.com/submit

) Biomed Central 